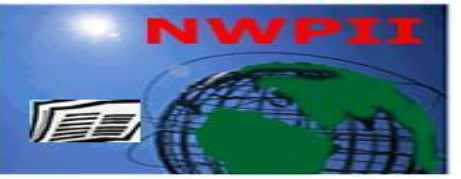

American Journal of Biomedical Sciences

ISSN: 1937-9080

nwpii.com/ajbms

\title{
Bacteriophage Treatment of Burn Wound Infection Caused by Pseudomonas aeruginosa PAO in BALB/c Mice
}

\author{
Seema Kumari ${ }^{1}$, Kusum Harjai ${ }^{1}$ and Sanjay Chhibber ${ }^{1}{ }^{*}$ \\ ${ }^{1}$ Basic Medical Sciences Building, Department of Microbiology, Panjab University, Chandigarh-160014, India. \\ *Corresponding author \\ Dr. Sanjay Chhibber \\ Professor \\ Basic Medical Sciences Building \\ Department of Microbiology \\ Panjab University \\ Chandigarh -160014 , India. \\ Phone: 91-0172-2534141, 91- 0172-2541770 \\ Fax: 91-0172-2541409; \\ E-mail: sanjaychhibber8@sify.com
}

Received: 22 April 2009; | Revised: 18 June 2009; | Accepted: 5July 2009

\begin{abstract}
Therapeutic potential of five purified and well characterized bacteriophages (Pa29, Pa30, Pa31, Pa33 and Pa34) was evaluated in thermally injured and Pseudomonas aeruginosa PAO infected mice. Efficacy of five $P$. aeruginosa phages was assessed on the basis of percentage survival of phage treated mice. Toxicity evaluation of all the phages, showed them to be non toxic as no sign of morbidity and mortality was observed in phage treated mice. Survival and stability of Pseudomonas specific phages was evaluated in mice and maximum phage count in various organs was obtained at $3 \mathrm{~h}$ which persisted till $24 \mathrm{~h}$ and no phage could be detected at $36 \mathrm{~h}$ post inoculation. The results of the study indicate that a single dose of phages intraperitoneally (i.p.) at highest multiplicity of infection (MOI) of 900, did not provide any protection from $P$. aeruginosa PAO induced burn wound infection in mice. Since a single application of Pseudomonas specific phages did not restrict the infection in thermally injured mice by $P$. aeruginosa PAO, the experiment was repeated by administering these phages at $24 \mathrm{~h}$ intervals, starting immediately after the infection up to $72 \mathrm{~h}$ at above mentioned MOI, even then no protection was observed in phage treated groups and results were comparable to control groups with $100 \%$ mortality $(P>0.05)$. The results of the present study show that, phages belonging to Podoviridae family, order Caudovirales were not effective in protecting $P$. aeruginosa infected thermally injured mice.
\end{abstract}

Keywords: Pseudomonas aeruginosa, bacteriophages, multiplicity of infection, Podoviridae, Myoviridae, Caudovirales. 


\subsection{Introduction}

Pseudomonas aeruginosa is a gram negative, versatile, opportunistic pathogen found along with other Pseudomonas spp. as part of normal flora of human skin $[1,2]$. It rarely causes infections in healthy individuals but can cause serious infections in immunocompromised hosts [3] which include patients with severe burn wounds $[4,5]$, cystic fibrosis patients [6], cancer patients [7] and patients with human immunodeficiency viral infection $[8,9]$. To initiate infection, $P$. aeruginosa usually requires a substantial breach in first-line defenses. Burn causes a breach in the protective skin barrier which suppresses the immune system, rendering the patients highly susceptible to bacterial infection and this opportunistic bacterium can then quickly colonize and infect the burn wound site [10]. The burn wound is considered as one of the major health problems in the world, the infection of which results in severe complications in patients who have sustained burns [11]. The denatured protein of the burn wound provides nutrition for the organisms. The infection is due to the combined effect of impairment of the host natural defense system, colonization of the burn wound site and systemic dissemination of the colonizing organisms [12]. Rapid colonization of burn site with $P$. aeruginosa $\mathrm{PAO}$ and its dissemination into distant organs via bloodstream often leads to bacteraemia, endotoxic shock and sepsis [13]. In case studies of burn patients who developed $P$. aeruginosa septicemia, mortality rate greater than $75 \%$ was observed $[14,15]$. Antibiotics that are administered orally are generally ineffective against most serious skin and soft tissue infections by $P$. aeruginosa [15]. Treatment of such infections is confounded by the innate and acquired resistance of $P$. aeruginosa to many antimicrobials agents [16]. Hence, the development of new therapeutic and prophylactic agents for the control of bacterial infection in patients with burn wounds is needed. An alternative to antibiotic therapy is phage therapy which involves the use of bacterial viruses to target bacterial infections [17-25].

Earlier we reported isolation, purification and characterization of bacteriophages specific to
Pseudomonas aeruginosa PAO from sewage samples collected from areas in and around Chandigarh, India [26]. In continuation of that work, the present study was planned to evaluate the efficacy of Pseudomonas specific phages in the experimental treatment of burn wound infection caused by $P$. aeruginosa PAO.

\subsection{Materials and Methods}

Bacterial strain and growth mediaStandard strain of Pseudomonas aeruginosa PAO obtained from Dr. Barbara H. Igleski, University of Rochester, New York (U.S.A) and maintained in our laboratory was used in this study. This organism was stored in $60 \%$ glycerol at $-80^{\circ} \mathrm{C}$ and when necessary, maintained on nutrient agar slants at $4^{\circ} \mathrm{C}$.

Phage isolation- Five Pseudomonas bacteriophages were isolated from sewage samples from different sources in and around Chandigarh area. The method of Cerveny et al. [27] was adopted for the isolation of phages from sewage samples. Phage titer was determined by soft agar overlay method as described by Adam [28]. The phages were purified, numbered Pa29, $\mathrm{Pa} 30, \mathrm{~Pa} 31, \mathrm{~Pa} 33$, and Pa34 and characterized on the basis of morphological, genomic studies and structural protein analysis [26].

Animals- Adult BALB/c mice, six weeks old, weighing 20-25 g were obtained from Central Animal House, Panjab University, Chandigarh. All animals were given antibiotic free diet (Hindustan Liver limited, Mumbai) and water $a d$ libitum. Animal study was conducted following protocols approved by the Institutional Animals Ethical Committee. All the experiments were carried out in triplicate. The error bars in graphs are representative of the standard deviation in each experiment.

Murine burn wound model- A third degree burn wound infection model was developed in mice using $P$. aeruginosa $\mathrm{PAO}$ following the method of Dale et al. [15]. 5 groups of mice (6 mice in each) were taken. Briefly, hair was clipped from the back of anesthetized mice and skin was denuded with a commercially available hair removing cream. Mice were anesthetized with ether fumes and burn was induced with the help of 
heated brass bar $(10 \times 10 \times 100 \mathrm{~mm})$ for 45 seconds (s). Immediately after the burn, all the mice were injected i.p. with $0.5 \mathrm{ml}$ of sterile physiological saline for fluid replacement to prevent overt shock and acetaminophen $(0.25 \mathrm{mg} / \mathrm{ml})$ was given as post burn analgesic in drinking water. Bacterial inoculum was prepared by inoculating $P$. aeruginosa in nutrient broth, incubating at $37^{\circ} \mathrm{C}$ overnight followed by repeated centrifugation $(10,000 \mathrm{rpm}$ for $10 \mathrm{~min})$ and washing, finally resuspending in normal saline. To determine $\mathrm{LD}_{100}$ (Lethal dose causing $100 \%$ mortality), value of $P$. aeruginosa culture, in group I - IV, doses ranging from $10^{2}$ to $10^{8} \mathrm{CFU} / \mathrm{ml}$ (colony forming unit $/ \mathrm{ml}$ ) were injected subcutaneously (s.c.) directly under the anterior end of the burn in mice, after a waiting period of $30 \mathrm{~min}$. In group $-\mathrm{V}$, burned mice were injected s.c. with Phosphate buffer saline (PBS, pH 7.2) and acted as control. Burned mice inoculated with bacteria and PBS were scored for their state of health on a arbitrary scale of 5 to 0 , based on progressive disease state reflected by several clinical signs. A normal and unremarkable condition was scored as 5; slight illness, defined as lethargy and ruffled fur, was scored as 4; moderate illness, defined as severe lethargy, ruffled fur, and hunched back, was scored as 3; severe illness, with the above signs plus exudative accumulation around partially closed eyes, was scored as 2; a moribund state was scored as 1; and death was scored as 0 . The dose giving $100 \%$ lethality was taken as the optimum $\mathrm{LD}_{100}$ dose.

Toxicity testing of phages -The toxicity of all Pseudomonas aeruginosa phages was evaluated in burned (compromised) mice according to the method of McVay et al. [5]. 5 groups of mice (6 mice in each) were taken. Each of these groups (burned but uninfected mice) were injected i.p. with $0.25 \mathrm{ml}$ of Pseudomonas specific phages of $10^{8} \mathrm{PFU} / \mathrm{ml}$ (plaque forming unit $/ \mathrm{ml}$ ) individually. The mice were scored for their state of health for 48-72 h. An arbitrary scale of $0-2$ was used to score the state of health of mice at different time intervals after i.p. administration of the phage suspension. A score of 2 indicated normal unremarkable health, 1 slight illness/ lethargy/ abnormal health, and 0 for death.
Survival and stability of phages - Survival and stability of Pseudomonas phages was measured in mice according to the method of Cerveny et al. [27]. Five groups of mice (12 mice in each) were taken and each group (uninfected or normal mice) was injected i.p. with one of the specific phage $\left(10^{8} \mathrm{PFU} / \mathrm{ml}\right)$. At $1,3,6,12,24$, 36,48 and $72 \mathrm{~h}$, blood was collected in screw capped vials containing $0.05 \mathrm{M}$ EDTA. Then mice were sacrificed and peritoneal fluid, skin and lungs were aseptically removed and subjected to phage count by plaque assay by employing double agar overlay technique [28].

Treatment with Pseudomonas phages - The efficacy of Pseudomonas phages to treat burn wound infection was evaluated in two separate experiments.

(a) Single phage dose: The therapeutic potential of phages, specific for $P$. aeruginosa PAO was evaluated for their ability to resolve burn wound infection in mice. Eleven groups of mice (10 mice in each) were used. Briefly, a full thickness burn was induced in mice and challenged with $\mathrm{LD}_{100}$ dose of $P$. aeruginosa culture s.c. directly under the anterior end of burn as described earlier. In group I-X, all the burned/infected mice were treated immediately with a single i.p. injection of $P$. aeruginosa $\mathrm{PAO}$ specific phages administered at various MOI (0.001, 0.01, 0.1, 1.0, 10, 100, 300, 500, 700 and $900)$. In group XI, burned and infected mice without any phage treatment were kept as control. Survival rate for control and phage treated groups was recorded up to $72 \mathrm{~h}$. Similar set of experiment was repeated for every phage separately.

(b) Multiple doses: In the second experiment, burned / bacterial challenged mice were injected i.p. with Pseudomonas specific phages (at highest MOI of 900) after every $24 \mathrm{~h}$ up to $72 \mathrm{~h}$ and effect of multiple doses of phages on the survival of animals was ascertained. 6 groups of mice (10 mice in each) were taken. Briefly, a third degree burn was induced in each group and challenged with $\mathrm{LD}_{100}$ dose of $P$. aeruginosa s.c. directly under the anterior end of burn as described earlier. In group $\mathrm{I}-\mathrm{V}$, all the burned/infected mice were treated immediately with a single i.p. injection of $P$. aeruginosa $\mathrm{PAO}$ specific phage individually administered at highest 
MOI (900). In group $\mathrm{V}$, burned /bacterial challenged mice without any phage treatment were kept as control. Survival rate for control and phage treated groups was recorded up to $72 \mathrm{~h}$.

Statistical analysis - Data are expressed as means \pm standard deviation (SD) of mean and statistical analysis was performed with Graph Pad Instat Software (Version 3.00, GraphPad Software, San Diego, California, USA) using student's $t$ test for calculations of mean and standard deviation while one-way analysis of variance (ANOVA) followed by Boneferroni test for multiple comparisons. Difference with $P \leq$ 0.05 was considered statistically significant.

\subsection{Results}

Determination of lethality of $P$. aeruginosa in thermally injured mice - Burned mice were challenged with bacterial doses ranging from $10^{2}$ to $10^{8} \mathrm{CFU} / \mathrm{ml}$. All burned mice inoculated s.c with $10^{7} \mathrm{CFU} / \mathrm{ml}$ died within $72 \mathrm{~h}$ as shown in Fig. 1. This dose was recorded as $\mathrm{LD}_{100}$ dose of bacteria and was used in all the experiments for the induction of infection. Death was attributed to septic shock due to the presence of organisms in the circulation of mice upon challenge with bacteria. All burned mice receiving PBS treatment only (control) did not show any signs of bacteraemia or slight illness over for a period of $72 \mathrm{~h}$.

Toxicity testing of $\boldsymbol{P}$. aeruginosa phages in mice - Pseudomonas phages did not manifest any illness and all the animals survived with a score of 2 (Fig. 2). This indicates that the either endotoxin present in the phage lysate was in non lethal concentration or the preparation was devoid of endotoxin suggesting that each individual phage was not toxic to thermally injured mice.

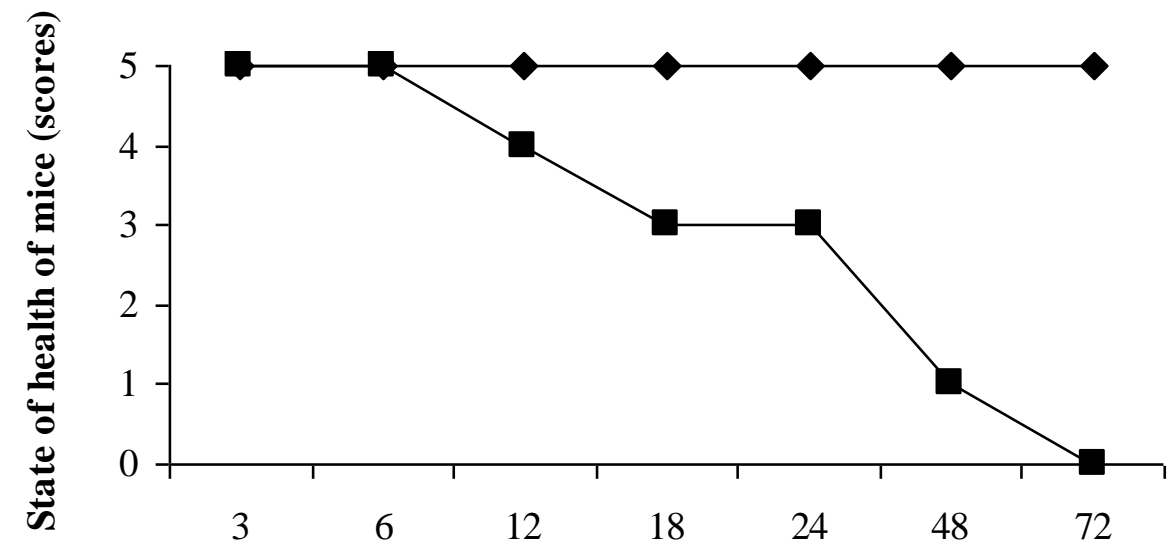

Time (h)

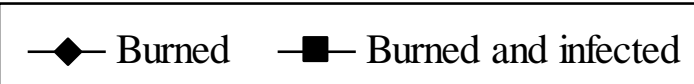

Figure. 1. Lethality of $10^{7} \mathrm{CFU} / \mathrm{ml}$ of $P$. aeruginos $\mathrm{PAO}$ in burned mice, $5=$ normal health; 4 = slight illness, defined as lethargy and ruffled fur; $3=$ moderate illness, defined as severe lethargy, ruffled fur, and hunched back; $2=$ severe illness, with the above signs plus exudative accumulation around partially closed eyes; $1=$ a moribund state; $0=$ death.

Survival and stability of Pseudomonas phages in mice - The survival and stability of isolated Pseudomonas specific phages, Pa29, Pa30, Pa31, Pa33 and Pa34 was determined in various body compartment of mice following i.p. injection $\left(3.0 \times 10^{8} \mathrm{PFU} / \mathrm{ml}\right)$ of each phage. The phage count was measured in blood, peritoneal fluid, lungs and skin of phage treated mice. Maximum phage count in blood, peritoneal fluid, lungs and skin was obtained at $3 \mathrm{~h}$ post injection 
in all the groups (Fig.3a-e). The phage count in peritoneal fluid of all Pseudomonas phage injected mice was slightly higher as compared to that in blood, lungs and skin samples. With increase in time, phage titer kept on decreasing in all body compartments. The phage count showed a significant decrease of 6-7 log units at $12 \mathrm{~h}$ and negligible counts were obtained at $24 \mathrm{~h}$ after injection. No phage could be isolated in peritoneal fluid, blood, lungs and skin samples at $36 \mathrm{~h}$ after phage treatment.

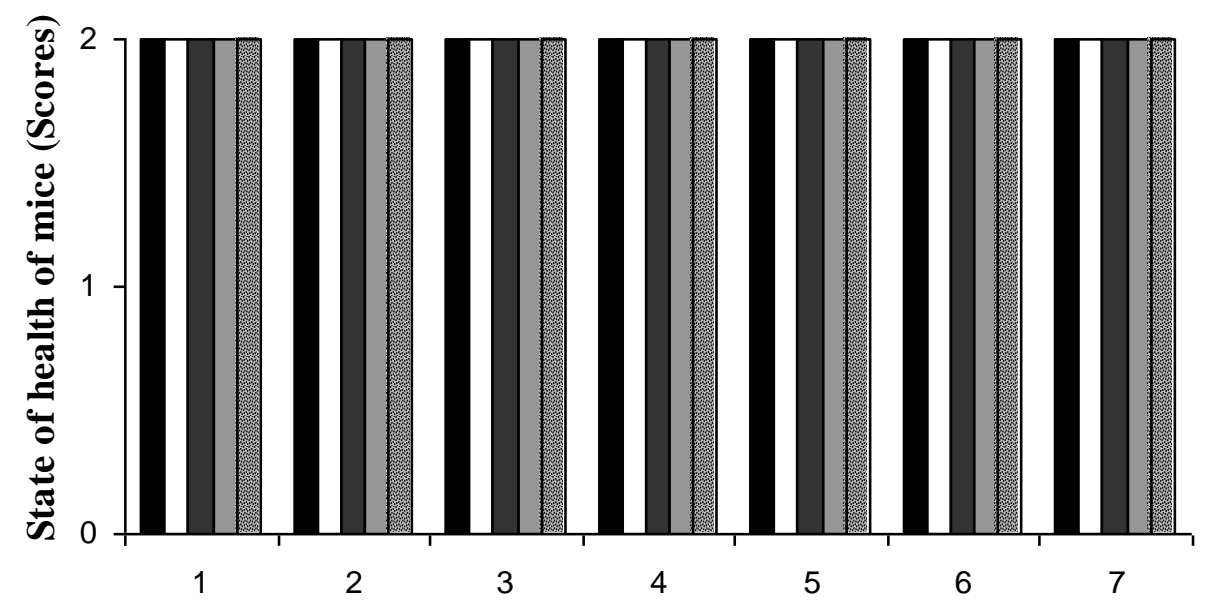

Time in days

$$
\begin{array}{lllll}
\text { 口 Pa29 } & \square \mathrm{Pa} 30 & \square \mathrm{Pa} 31 & \square \mathrm{Pa} 33 & \text { 口 } \mathrm{Pa} 34
\end{array}
$$

Figure. 2. Toxicity of the phage treatments; $2=$ normal or unremarkable condition, $1=$ slight illness, $0=$ Death.

Efficacy of Pseudomonas phages in the treatment of $P$. aeruginosa PAO induced burn wound infection in mice -To optimize the phage dose for the treatment of $P$. aeruginosa induced burn wound infection in mice, single i.p. dose of each $P$. aeruginosa PAO specific phage (Pa29, Pa30, Pa31, Pa33 and Pa34) was injected at varying MOI ranging from 0.001 to 900 , in separate groups of burned and $P$. aeruginosa $\mathrm{PAO}$ infected mice. At lower MOI (0.001 - 700), none of the Pseudomonas phages was able to protect burned mice from bacteraemia. Even at very high MOI (900), a non significant $(P>0.05)$ difference in survival rate of all phage treated groups was observed as compared to burned/ infected mice treated with only nutrient broth (control) at $72 \mathrm{~h}$ post infection.

Even when multiple doses of phages were injected at every $24 \mathrm{~h}$ interval following burn infection, similar pattern of survival rates was observed in all phage treated and untreated control groups. The results obtained with even at highest tested MOI (900) were quite discouraging. A non significant difference $(P>0.05)$ between survival rates of control and phage treated groups was observed (Fig. 4).

\subsection{Discussion}

Therapeutic potential of five well characterized phages of Pseudomonas aeruginosa PAO [26] isolated from sewage samples was evaluated in this study for the treatment of burn wound infection. There are reports available in literature where phages have been used to treat variety of bacterial infections in animal model systems [29-37], the information in this regard to treat burn wound infection is scanty. Soothill [38] demonstrated the ability of phages to prevent rejection of skin grafts in guinea pigs. On this basis it was suggested that bacteriophages can play a role in the treatment of burn wound 
infection by $P$. aeruginosa. Later, using cocktail of three different $P$. aeruginosa specific phages, Mcvay et al., [5] showed protection against fetal infection with $P$. aeruginosa in mice. Clinical

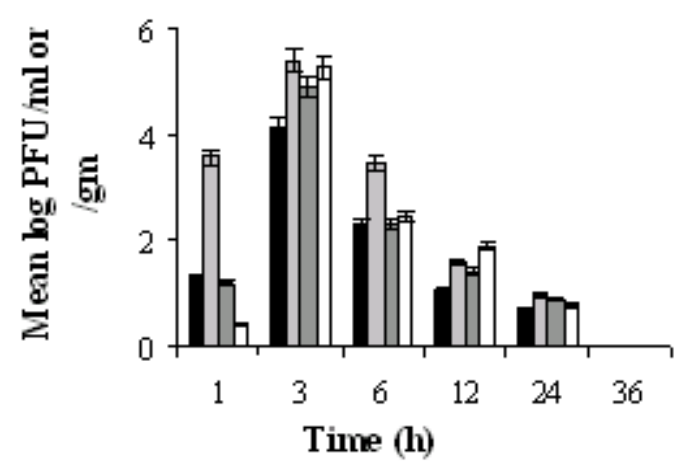

(a)

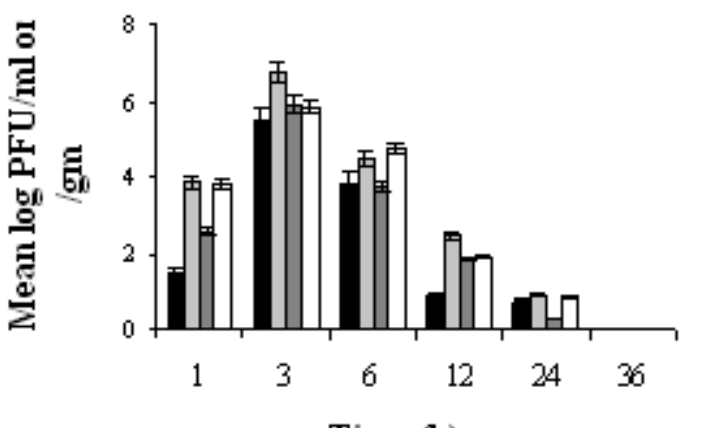

Time (h) trials have been initiated on the basis of this information where a cocktail of phages targeted against $P$. aeruginosa and Staphylococcus aureus is under way in Belgium [39].

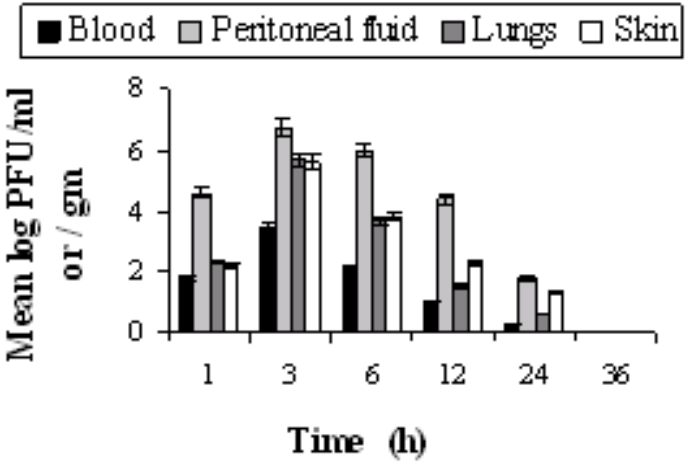

(b)

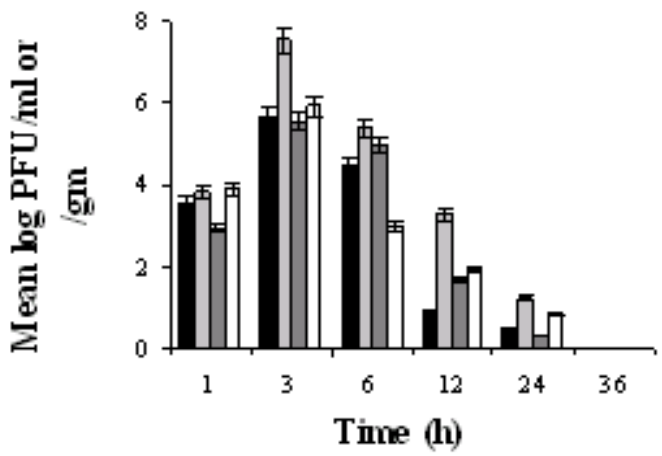

(d)

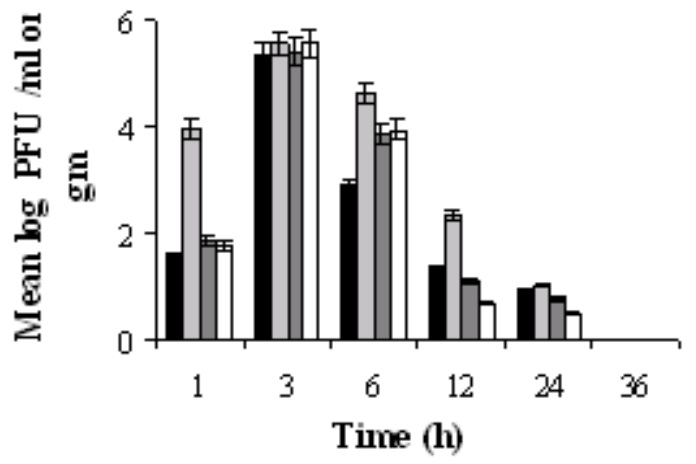

(e)

Figure. 3. Phage count in blood, peritoneal fluid, lungs and skin at varying time periods after administration of $P$. aeruginosa PAO specific phages. (a) Phage Pa29; (b) Phage Pa30; (c) Phage Pa31; (d) Phage Pa33; (e) Phage Pa34 (each having titer of $10^{8} \mathrm{PFU} / \mathrm{ml}$ ) in $\mathrm{BALB} / \mathrm{c}$ mice. 


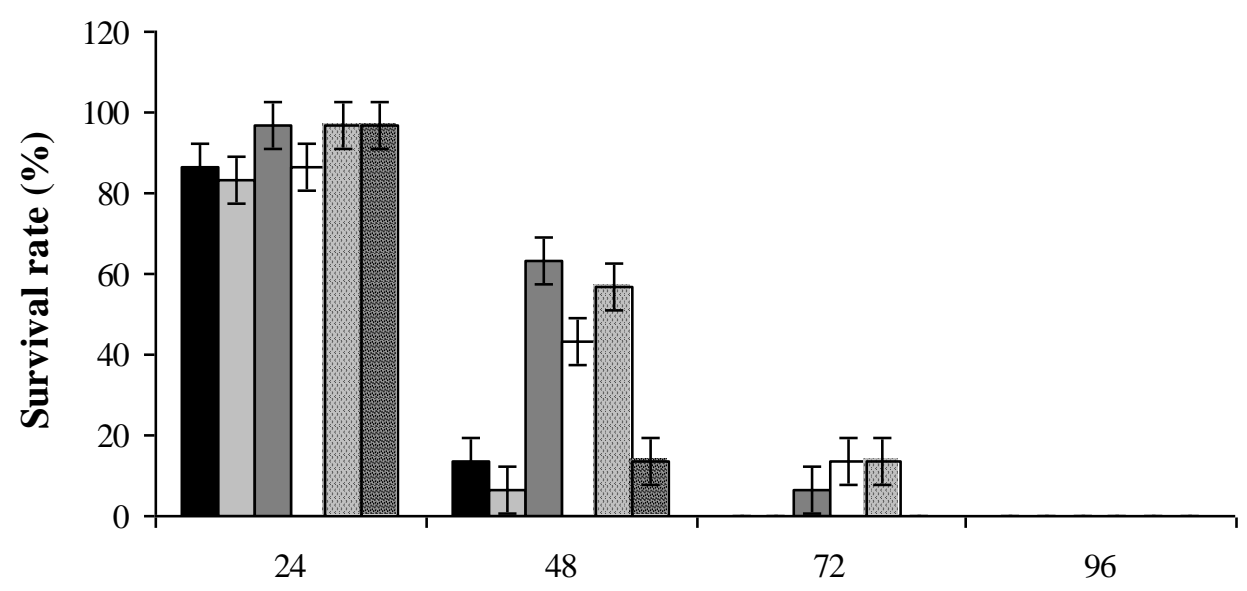

Time (h)

\begin{tabular}{|ll|}
$\square$ Control & $\square$ Pa29 phage treated \\
$\square$ Pa30 phage treated & $\square$ Pa31 phage treated \\
$\square$ Pa33 phage treated & $\quad$ Pa34 phage treated \\
\hline
\end{tabular}

Figure. 4. Percentage survival of burned and $P$. aeruginosa PAO infected mice following treatment with different phages at MOI of 900 .

Pseudomonas phages in this study when tested in thermally injured mice were found to be non toxic, devoid of any bacterial contamination in phage suspension and hence phage preparation was considered safe enough to be administered to compromised mice $[40,5]$. The other critical parameters that affect phage therapy were also evaluated in terms of phage adsorption rate, burst size, latent period and initial phage dose. All the phages selected were found to have shorter latent period and burst size making them most appropriate agents for phage therapy. In addition, the clearance of the phage particles from the body fluids by the reticuloendothelial system (RES) is also crucial in determining their potential as therapeutic agents. Although phages entered into the blood stream after $1 \mathrm{~h}$ but they achieved the maximum count at $3 \mathrm{~h}$ post injection. In earlier studies also, it has been observed that phages take a maximum of $2-4 \mathrm{~h}$ to reach their peak in the blood stream [41, 42]. The phage count however significantly declined at $24 \mathrm{~h}$ leading to total absence of phage particles at $36 \mathrm{~h}$ post injections in all the body compartments of mice.
None of the five phages was found to be capable of clearing bacteria from the burn wound site even when used at a high MOI of 900 inspite of their potential to inhibit bacteria in vitro. In our laboratory, using Klebsiella pneumoniae B5055 phages, we were able to restrict the growth of bacteria in the same model of burn wound at a MOI of 1.0 [43]. These results indicate that their exist an intricate molecular mechanism in the phage / bacterium system. In fact, according to Skurnik and Strauch [44], all phage /host systems are not likely to behave identically in vivo. The differences in their action may arise due to number of reasons. It is likely that in vivo the bacterium may become resistant to phages due to mutation thereby losing the receptors for phage on bacteria. Since attachment to the receptors is the initial step in the phage infection, hence such loss of receptors may influence the in vivo susceptibility of the pathogens to bacteriophages. However, no alteration in the sensitivity of $P$. aeruginosa, PAO isolated from different organs to phages was observed in this study indicating absence of such mutants in vivo. In addition, a phage may also 
become resistant due to lysogeny which renders the bacterium not only immune to the original phage but also to related phages [44]. According to these workers, phage resistance may also be due to horizontal acquisition of a restriction modification system that degrades the injected phage nucleic acid or due to mutation in gene whose product is essential for phage replication assembly. These observations point toward the complexicity of the phage / bacterium interactions in the animal model systems. In fact mathematical model adopted by Weld et al. [45] to monitor phage growth in rats failed to predict their growth in vivo. The inability of Pseudomonas specific bacteriophages to control $P$. aeruginosa induced infection in thermally injured mice may also be attributed to biofilm forming property of this bacteria. $P$. aeruginosa has tendancy to form biofilm consisting of bacterial communities embedded in a mucoid exopolysaccharide matrix [46]. Biofilms are resistant to antimicrobial agents as well as to host defense mechanisms and hence are difficult to eradicate. Failure of phage therapy possibly due to inability of these phages to penetrate into deeper layers of the thicker biofilms [47] may be another reason which did not restrict the bacterial growth in this animal model system. It is known that biofilms from time to time shed these protected bacterial populations in the system thereby aggravating the clinical choice of disease [48]

The results of this study therefore suggest that future research should concentrate on to answer the intricate mechanisms making phages ineffective or effective in vivo, which in turn influence bacterial growth. Such information will help in the development of therapeutic phages against different organisms, an approach which has received lots of attention of scientists the world over to tackle the menace of drug resistance among pathogens.

\section{Acknowledgement}

The fellowship grant received by Ms. Seema Kumari from University Grant Commission (UGC) is thankfully acknowledged.

\section{References}

1. Larson, E.L.; Gomez-Duarre, C.; Lee, L.V.; Kain, D.J.; Keswick, B.H. Microbial flora of the hands of homemakers. Am J Infect Control, 2002, 31, 72-79.

2. Mooij, M.J.; Drenkard, E.; Llamas, M.A.; Vandenbroucke-Grauls, C.M.J.E.; Savelkoul, P.H.M.; Ausubel, F.M.; Bitter, W. Characterization of the integrated filamentous phage Pf5 and its involvement in small-colony formation. Microbiology, 2007, 153, 17901798.

3. Bodey, G.P.; Bolivar, R.; Fainstein, V.; Jadeja, L. Infections caused by Pseudomonas aeruginosa. Rev Infect Dis, 1983, 5, 279-313.

4. Holder, I. A. 1993. Pseudomonas aeruginosa burn infections: pathogenesis and treatment, $\mathrm{p}$. 275-295. In M. Campa, M. Bendinelli, and H. Friedman (ed.), Pseudomonas aeruginosa as an opportunistic pathogen. Plenum Press, New York, N.Y.

5. McVay, C.; Velasquez, S.M.; Fralick, J.A. Phage therapy of Pseudomonas aeruginosa infection in a mouse burn wound model. Antimicrob Agents Chem, 2007, 51, 19341938.

6. Doring, G. Pseudomonas aeruginosa infection in cystic fibrosis patients, 1993, p. 245-273. In M. Campa, M. Bendinelli, and H. Friedman (ed.), Pseudomonas aeruginosa as an opportunistic pathogen. Plenum Press, New York, N.Y.

7. Bergen, G.A.; Shelhamer, J.H. Pulmonary infiltrates in the cancer patient. New approaches to an old problem. Infect Dis Clin N Am, 1996, 10, 297-325.

8. Fichtenbaum, C.J.; Woeltje, K.F.; Powderly, W.G. Serious Pseudomonas aeruginosa infections in patients infected with human immunodeficiency virus: a case-control study. Clin Infect Dis, 1994, 19, 417-422.

9. Kukavica-Ibrulj, I.; Bragonzi, A.; Paroni, M.; Winstanley, C.; Sanschagrin, F.; O'Toole, G.A.; Levesque, R.C. In vivo growth of Pseudomonas aeruginosa strains PAO1 and PA14 and the hypervirulent strain LESB58 in a rat model of chronic lung infection. $J$ Bacteriol, 2008, 190, 2804-2813. 
10. DeBoer, S.; O'Connor, A. Prehospital and emergency department burn care. Crit Care Nurs Clin N Am, 2004, 16, 61-7.

11. Zorgani, A.; Zaidi, M.; Ranka, R.; Shahen, A. The pattern and outcome of septicaemia in a burns intensive care unit. Ann Burns and Fire Disasters, 2002, 15, 179-82.

12. Kehinde, A.O.; Ademola, S.A.; Okesola, A.O.; Oluwatosin, O.M.; Bakare, R. Pattern of bacterial pathogens in burn wound infections in Ibadan, Nigeria. Annals of Burns and Fire Disasters, 2004, vol. XVII - n.1.

13. Church, D.; Elsayed, S.; Reid, O.; Winston, B.; Lindsay, R. Burn wound infections. Clin Microbiol Rev, 2006, 19, 403-434.

14. Green, J.W.; Wenzel. R.P. Postoperative wound infection: a controlled study of the increased duration of hospital stay and direct cost of hospitalization. Ann Surg, 1977, 185, 264-268.

15. Dale, R.M.K.; Schnell, G.; Wong, J.P. Therapeutic efficacy of "Nubiotics" against burn wound infection by Pseudomonas aeruginosa. Antimicrob Agents Chem, 2004, 48, 2918-2923.

16. MacManus, A.T.; Mason, A.D.; Jr., McManus, W.F.; Pruitt, B.A.; Jr. Twenty-five year review of Pseudomonas aeruginosa bacteremia in a burn center. Eur J Clin Microbiol, 1985, 4, 219-223.

17. Sulakvelidze, A.; Alavidze, Z.; Morris, J.G. Jr. Bacteriophage therapy. Antimicrob Agents Chem, 2001, 45, 649-659.

18. Duckworth, D.H.; Gulig, P.A. Bacteriophages: potential treatment for bacterial infections. BioDrugs, 2002, 16, 57-62.

19. Inal, J.M. Phage therapy: a reappraisal of bacteriophages as antibiotics. Arch Immunol Ther Exp, (Warsaw) 2003, 51, 237-244.

20. Mathur, M.D.; Bidhani, S.; Mehndiratta, P.L. Bacteriophage therapy: an alternative to conventional antibiotics. J Assoc Physicians India, 2003, 51, 593-596.

21. Theil, K. Old dogma, new tricks-21st century phage therapy. Nat Biotech, 2004, 22, 31-36.

22. Matsuzaki, S.; Rashel, M.; Uchiyma, J.; Ujihara, T.; Kuroda, M.; Ikeuchi, M.; Fujieda, M.; Wakiguchi, M.; Imai, S. Bacteriophage therapy: a revitalized therapy against bacterial infectious diseases. J Infect Chemother, 2005, 11, 211-219.

23. Hanlon, G.W. Bacteriophages: an appraisal of their role in the treatment of bacterial infections. Int J Antimicrob Agents, 2007, 30,118-128.

24. Skurnik, M.; Pajunen, M.; Kiljunen, S. Biotechnological challenges of phage therapy. Biotechnol Lett, 2007, 29, 995-1003.

25. Chhibber, S.; Kaur, S.; Kumari, S. Therapeutic potential of bacteriophage in treating Klebsiella pneumoniae B5055-mediated lobar pneumonia in mice. J Med Microbiol, 2008, 57, 1508-13.

26. Kumari, S.; Harjai, K.; Chhibber, S. Characterization of Pseudomonas aeruginosa PAO specific bacteriophages isolated from sewage samples. Am J Biomed Sci, 2009, 1(2), 91-102.

27. Cerveny, K.E.; DePaola, A.; Duckworth, D.H.; Gulig, P.A. Phage therapy of local and systemic disease caused by Vibrio vulnificus in iron- dextran -treated mice. Infect Immun, 2002, 70(11), 6251-6262.

28. Adams, M. (ed.) Bacteriophages. Interscience Publishers, London, United Kingdom 1959.

29. Barrow, P.; Lovell, M.A.; Berchieri, A. Jr. Use of lytic bacteriophages for control of experimental Escherichia coli septicemia and meningitis in chickens and calves. Clin Diagn Lab Immunol, 1998, 5, 294-298.

30. Biswas, B.; Adhya, S.; Washart, P.; Paul, B.; Trostel, A.N.; Powell, B.; Carlton, R.; Merril, C.R. Bacteriophage therapy rescues mice bacteremic from a clinical isolate of vancomycin-resistant Enterococcus faecium. Infect Immun, 2002, 70, 204-210.

31. Bull, J.J.; Levin, B.R.; DeRouin, T.; Walker, N.; Bloch, C.D. Dynamics of success and failure in phage and antibiotic therapy in experimental infections. BMC Microbiol, 2002, 2, 35-45.

32. Loc Carrillo, C.L.; Atterbury, R.D.J.; ElShibiny, A.; Connerton, P.L.; Dillon, E.; Scott, A.; Connerton, I.F. Bacteriophage therapy to reduce Camplylobacter jejuni colonization of broiler chickens. Appl Environ Microbiol, 2005, 71, 6554-6563.

33. Vinodkumar, C.S.; Neelagund, Y.F.; Kalsurmath, S. Bacteriophage in the treatment 
of experimental septicemic mice from a clinical isolate of mutidrug resistant Klebsiella pneumoniae. J Communicable Dis, 2005, 37, 18-29.

34. Wills, Q.F.; Kerrigan, C.; Soothill, J.A. Experimental bacteriophages protection against Staphylococcus aureus abscesses in a rabbit model. Antimicrob Agents Chemother, 2005, 49, 1220-1221.

35. Capparelli, R.; Ventimiglia, I. ; Roperto, S.; Fenizia, D.; Iannelli, D. Selection of an Escherichia coli O157:H7 bacteriophage for persistence in the circulatory system of mice infected experimentally. Clin Microbiol Infect, 2006, 12, 248-253.

36. Wang, J.; Hu, B.; Xu, M.; Yan, Q.; Liu, S.; Zhu, X.; Sun, Z.; Reed, E.; Ding, L.; Gong, J.; Li, G.Q.; Hu, J. Use of bacteriophage in the treatment of experimental animal bacteremia from imipenem-resistant Pseudomonas aeruginosa. Int J Mol Med, 2006, 17, 309-317.

37. Vinodkumar, C.S.; Kalsurmath, S.; Neelagund Y.F. 2008. Utility of lytic bacteriophage in the treatment of multidrug-resistant Pseudomonas aeruginosa septicemia in mice. Ind J Pathol Microbiol, 51(3), 360-366.

38. Soothill, J.S. Bacteriophage prevents destruction of skin grafts by Pseudomonas aeruginosa. Burns, 1994, 20, 209-211.

39. Merabishvili, M.; Pirnay, J.-P.; Verbeken, G.; Chanishvili, N.; Tediashvili, M.; Lashkhi, N.; Glonti, T.; Krylov, V.; Mast, J.; Parys, L.V.; Lavigne, R.; Volckaert, G.; Mattheus, W.; Verween, G.; Corte, P.D.; Rose, T.; Jennes, S.; Zizi, M.; Vos, D. D.; Vaneechoutte, M. Quality-controlled small-scale production of a well- defined bacteriophage cocktail for use in human clinical trials. PLoS ONE, 2009, 4(3), 110.

40. Benedict, L.R.N.; Flamiano, R.S. Use of bacteriophages as therapy for Escherichia coli- induced bacteremia in mouse models. Phil $J$ Microbiol Infect Dis, 2004, 33(2), 47-51.

41. Bogovazova, G.G.; Voroshilova, N.N.; Bondarenko, V.M. The efficacy of Klebsiella pneumoniae bacteriophage in the therapy of experimental Klebsiella infection. $Z h$ Mikrobiol Epidemiol Immunobiol, 1991, 4, 5-8 (in Russian).

42. Bogovazova, G.G.; Voroshilova, N.N.; Gorbatkova, G.A.; Bondarenko, V.M.; Kazakova, T.B.; Mamleeva, A.G.; Sirnov, V.D.; Glukharev, I.A.; Erastova, E.I.; Krylov, I.A.; Ovcherenko, T.M.; Baturo, A.P.; Yalsyk, G.V.; Arefyeva, N.A. Immunobiological properties and therapeutic effectiveness of preparations from Klebsiella bacteriophages. Zh Mikrobiol Epidemiol Immunobiol, 1992, 3, 30-33 (in Russian).

43. Kumari, S.; Harjai, K.; Chhibber, S. Efficacy of bacteriophage treatment in murine burn wound infection induced by Klebsiella pneumoniae. J Microbiol Biotechnol, 2009, 19(6), 622-628

44. Skurnik, M.; Strauch, E. Phage therapy: Facts and fiction. Int $J$ of Med Microbiol, 2006, 296, 5-14.

45. Weld, R.J.; Butts, C.; Heinemann, J.A. Models of phage growth and their applicability to phage therapy. J Theor Biol, 2004, 227, 1-11.

46. Drenkard, E.; Ausubel, F.M. Pseudomonas biofilm formation and antibiotic resistance are linked to phenotypic variation. Nature, 2002, 416, 740-3.

47. Doolittle, M.M.; Cooney, J.J.; Caldwell, D.E. Tracing the interactions of bacteriophage using fluorescent and chromogenic probes. $J$ Ind Microbiol, 1996, 16, 331-341.

48. Donlan, R.M.; Costerton, J.W. Biofilms: survival mechanisms of clinically relevant microorganis. Clin Microbiol Rev, 2002, 15(2), 167-193. 